\title{
ESTUDO DE DOSAGEM DO CONCRETO LEVE COM AR INCORPORADO
}

\author{
LIGHTWEIGHT CONCRETE DOSING STUDY WITH INCORPORATED AIR
}

Naira Fabiana Paris ${ }^{1}$

Gabriela Cassol ${ }^{2}$

\section{RESUMO}

O concreto é um dos materiais de maior utilização nas edificações e uma de suas maiores vantagens é a resistência à compressão (LIMA; BARBOZA; GOMES, 2003). Porém por outro lado, apresenta um peso específico elevado, o que se caracteriza como uma desvantagem. O concreto com ar incorporado foi inicialmente utilizado para melhorar sua resistência ao gelo e ao degelo, porémfoi descoberto que o uso do aditivo incorporador de ar diminuiu significativamente seu peso específico em decorrência das microbolhas de ar presentes em sua estrutura. Apesar de interferir positivamentena diminuição do peso específico, estudos também compravam que o uso do aditivo também afeta outras propriedades muito importantes do concreto como a resistência à compressão e trabalhabilidade. Dessa maneira esse trabalho teve por objetivo determinar a possibilidade de dosar um concreto leve com aditivo incorporador de ar que obtivesse um valor de resistência à compressão próxima ao concreto convencional. O programa experimental foi realizado no Laboratório de Materiais e Solos da Universidade Alto Vale do Rio do Peixe (UNIARP).No processo foi realizado a caracterização dos materiais, em seguida o estudo de dosagem do concreto, sendo um traço de referência do concreto convencional $(1: 3,93)$ e três traços com aditivo incorporador de ar sobre o traço de referência com diferentes porcentagens de aditivo sobre a massa de cimento $(0,20 \%, 0,40 \%$ e $0,50 \%)$ e, por fim o ensaio no estado endurecido e a análise dos resultados.

Palavras-Chave: Concreto leve. Ar incorporado. Resistencia.

\footnotetext{
${ }^{1}$ Acadêmico do Curso de Engenharia Civil da Universidade Alto Vale do Rio do Peixe (UNIARP). Email: naira.paris@hotmail.com.

2 Professora Orientadora. Graduado em Engenharia Civil, pela Universidade do Oeste de Santa Catarina (UNOESC), Mestrado em Engenharia Civil, pela Universidade Estadual Paulista "Júlio de Mesquita Filho" (UNESP) campus de Ilha Solteira e docente do Curso de Engenharia Civil da Universidade Alto Vale do Rio do Peixe.
} 


\section{ABSTRACT}

Concrete is one of the materials most used in buildings and one of its main advantages is the compressive strength (LIMA; BARBOZA; GOMES, 2003). However, on the other hand, it has a high specific weight, which is characterized as a disadvantage. The concrete with incorporated air was initially used to improve its resistance to freeze and thaw, but it was found that the use of the additive air incorporating significantly decreased its specific weight as a result of the air microbubbles present in its structure. Although it interfered positively in the reduction of specific weight, studies also prove that the use of the additive also affects other very important properties of the concrete like the resistance to compression and workability. In this way, the objective of this work was to determine the possibility of dosing a lightweight concrete with air incorporating additive that obtained a compressive strength value close to conventional concrete. The experimental program was carried out at the Materials and Soils Laboratory of the Alto Vale do Rio do Peixe University (UNIARP). In the process was carried out the characterization of the materials, then the dosage study of the concrete, being a trace of reference of conventional concrete $(1: 3,93)$ and three traces with incorporated air on the reference trace with different percentages of additive on the cement mass $(0,20 \%, 0,40 \%$ and $0,50 \%)$ and, finally the test in the hardened state and analysis of the results.

Keywords: Lightweight concrete. Incorporated air. Resistance.

\section{INTRODUÇÃO}

O concreto é um dos materiais de construção mais utilizados pela humanidade, as razões para que isso aconteça são diversas, entre elas estão a facilidade de encontrar os materiais para sua composição, o seu custo relativamente baixo, a facilidade com que pode ser produzido, a sua capacidade de adaptação a diversos tipos de fôrma e tamanhos e também a sua excelente resistência (LIMA; BARBOZA; GOMES, 2003).

Segundo Pinheiro e Crivelaro (2016) o concreto é constituído pela mistura de um aglomerante, um agregado miúdo, um agregado graúdo, água e, em algumas ocasiões, aditivos. A relação de quantidade desses materiais é chamada de traço, sendo o traço o encarregado pela resistência do concreto.

Os aditivos são, de acordo com Neville (2016) capazes de atribuir certas vantagens ao concreto em situações em que existam grandes dificuldades ou 
dificuldades insuperáveis para o uso do concreto (convencional), e essa é a razão para o crescente uso desses produtos.

De acordo com a empresa fornecedora de materiais para construção civil Diprotec (2018) os incorporadores de ar são aditivos que adicionados na fase de amassamento na produção do concreto, incorporam e distribuem uniformemente as bolhas de ar no mesmo, e essas bolhas permanecem no produto depois de endurecido. Segundo a Diprotec (2018) o aditivo, entre outras aplicações é recomendado no uso de concretos leves e apresenta vantagens como aumento de durabilidade, redução de permeabilidade, água de amassamento, densidade, etc.

A substituição de parte dos materiais sólidos por ar no concreto, através da introdução do mesmo, resulta na diminuição da massa específica do concreto em relação ao concreto convencional, caracterizando-o assim como concreto leve (ROSSIGNOLO, 2009).

A consequente diminuição da massa específica no concreto leve é um fator que pode apresentar vantagens nos elementos estruturais, pois pode apresentar menor dimensão nos elementos de seção transversal, acarretando assim um menor peso nas fundações e, também em alguns casos pode facilitar construções em solos que apresentam baixa capacidade de suporte (NEVILLE, 2016). É importante lembrar que, de acordo com Neville (2016) os vazios de ar no concreto, sejam eles resultantes do aditivo ou de qualquer outra origem, afetam a resistência do concreto.

Com a disponibilidade de tantos materiais para a construção civil e também o surgimento de tantos outros, é possível encontrar um material que se adeque às exigências de cada caso, só é necessário conhecer esses materiais e saber utilizá-los e dosá-los.Com o crescente desenvolvimento da tecnologia os laboratórios estão cada vez mais equipados e capazes de realizar ensaios e testes para simular o comportamento do concreto com diferentes tipos de aditivos, inclusive o incorporador de ar.

Dessa maneira, o intuito desse trabalho é conhecer melhor as características e propriedades do concreto com adição de ar incorporado através de um estudo de dosagem, e, comparar a resistência à compressão do concreto leve com aditivo incorporador de ar e o concreto convencional e, consequentemente, ter a percepção de quando utilizá-lo e em quais casos ele é ou não recomendável se 
comprado ao concreto convencional.

\section{MATERIAIS E MÉTODOS}

Este capítulo irá apresentar o programa experimental realizado no Laboratório de Materiais e Solos da Universidade Alto Vale do Rio do Peixe (UNIARP) em Caçador. Primeiramente foi realizado a caracterização do agregado miúdo e agregado graúdo, e na seguida foram confeccinados quatro traços de concreto, sendo um traço de concreto convencional de referância e três traços de concreto com ar incorporado com diferentes porcentagens de aditivo sobre a massa de cimento. Em seguida foram realizados os ensaios no estado fresco do concreto e logo após os corpos de prova foram moldados, por fim foi realizado o ensaio no estado endureciso do concreto por rompimento dos corpos de prova aos 07,14 e 28 dias para analisar a resistência à compressão.

MATERIAIS

\section{Cimento Portland}

O tipo de cimento que foi utilizado para realização do trabalho, entre os diversos que estão disponíveis no mercado atualmente, é o CP II Z - 40, o Cimento Portland composto com pozolana. O cimento foi escolhido, porque é facilmente encontrado no mercado e possui ampla aplicação em diversas obras, sendo recomendado para obras estruturais. O CP II Z possui três classes de resistência adquirida aos 28 dias de idade: 25,32 e $40 \mathrm{MPa}$, sendo o $40 \mathrm{MPa}$, o utilizado no trabalho.

\section{Agregado miúdo}

O agregado miúdo que foi utilizado na realização do presente estudo, foi a areia fina, procedente da região de Porto União - Santa Catarina, com massa específica de 2,66 g/ $\mathrm{cm}^{3}$, massa unitária de $1,468 \mathrm{~g} / \mathrm{dm}^{3}$ e módulo de finura de 1,84. 


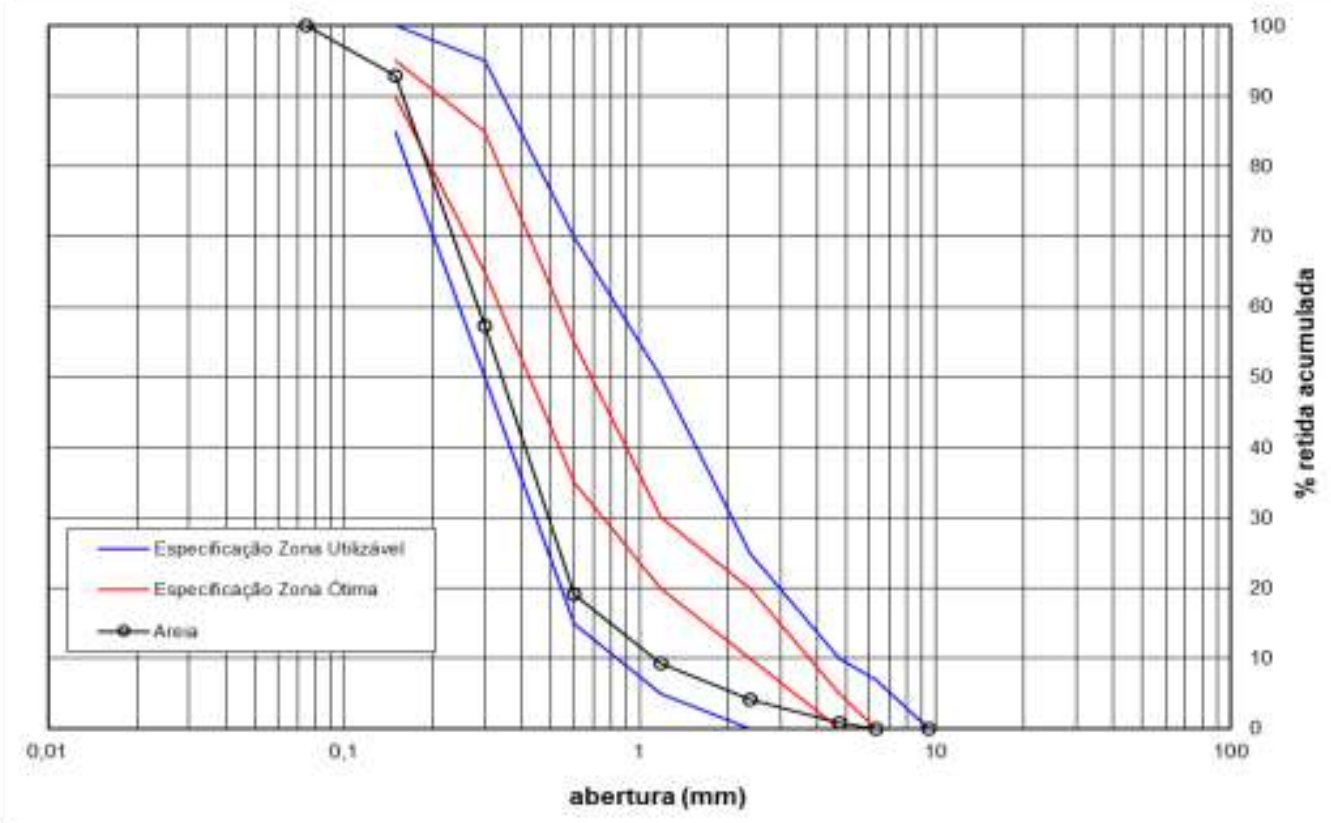

Figura 1 - Curva granulométrica do agregado miúdo

Fonte: O próprio autor

\section{Agregado graúdo}

O agregado graúdo utilizado para o desenvolvimento deste estudo, foi a brita 01, procedente de uma pedreira no município de Caçador - Santa Catarina, com massa específica de $1,84 \mathrm{~g} / \mathrm{cm}^{3}$, massa unitária de $1,380 \mathrm{~kg} / \mathrm{dm}^{3}$ e módulo de finura de 1,39. 
Abertura das peneiras ( $\mathrm{mm}$ )

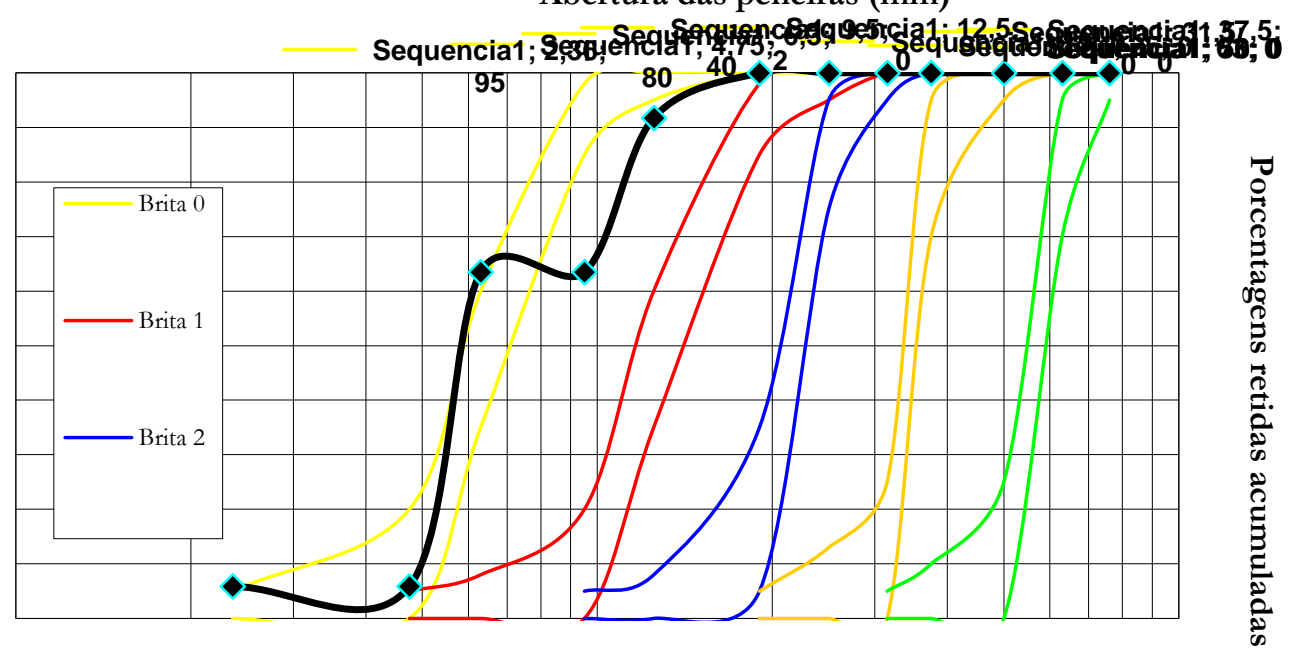

Figura 2 - Curva granulométrica do agregado graúdo

Fonte: O próprio autor

\section{Aditivo Incorporador de Ar}

O aditivo incorporador de ar utilizado neste trabalho para a produção do concreto foi o Centrament Air 200 - Aditivo incorporador de ar para concreto e argamassa da MC Bauchemie.

Segundo a ficha técnica do produto químico da Bauchemie, o método de ação do aditivo é produzir inúmeras bolhas de ar no concreto de diâmetro menor que $0,3 \mathrm{~mm}$ em concretos e argamassas, o aditivo pode ser usado tanto em concreto usinado como em concretos produzidos na obra, e pode ser utilizado juntamente com outros aditivos da Bauchemie.

$\mathrm{O}$ aditivo possui massa específica de $1 \mathrm{~g} / \mathrm{cm}^{3}$ e a recomendação do fabricante é que se utilize de 0,02 à $0,5 \%$ de aditivo sobre a massa do cimento.

\section{Água de Amassamento}

A água de amassamento utilizada no desenvolvimento dos traços do concreto em estudo éde procedência do poço artesiano que abastece a UNIARP em Caçador - Santa Catarina. 
MÉTODOS

\section{Método de dosagem dos traços de concretos}

O método de dosagem que foi utilizado na realização deste trabalho é o método desenvolvido pelo Instituto de Pesquisas Tecnológicas (IPT) e pela Escola Politécnica da Universidade de São Paulo (EPUSP), ou seja, o método IPT/EPUSP.

Na dosagem do concreto, utilizou-se o traço referência 1:3,93 que foi baseado no traço utilizado por Barbar (2016), sobre esse traço foram realizadas algumas alterações mediante alguns ensaios pré realizados no laboratório. Foi definido para o traço desse concreto convencional de referência um teor de argamassa de $59 \%$ e relação água/cimento de 0,45 . Com base no traço convencional de referência desenvolveram-se mais três traços para o concreto com ar incorporado com diferentes porcentagens do aditivo sobre a massa de cimento. A descrição dos traços segue na tabela 01.

Tabela 1: Traços do concreto

\begin{tabular}{lllll}
\hline Traço & $\begin{array}{l}1: 3,93 \\
\text { (Convencional/ } \\
\text { referência) }\end{array}$ & $\begin{array}{l}1: 3,93 \text { com } \\
0,5 \% \text { aditivo }\end{array}$ & $\begin{array}{l}1: 3,93 \text { com } \\
0,4 \% \text { aditivo }\end{array}$ & $\begin{array}{l}1: 3,93 \text { com 0,20\% } \\
\text { aditivo }\end{array}$ \\
\hline Cimento (kg) & 7,100 & 7,100 & 7,100 & 7,100 \\
\hline Areia (kg) & 13,500 & 13,500 & 13,500 & 13,500 \\
\hline Brita (kg) & 14,340 & 14,340 & 14,340 & 14,340 \\
\hline Água (L) & 3,200 & 3,200 & 3,200 & 3,200 \\
\hline Aditivo (g) & - & 44,500 & 28,400 & 14,20 \\
\hline
\end{tabular}

Fonte: O próprio autor

\section{Ensaios do Concreto}

O ensaio para determinar a consistência do concreto produzido foi realizado segundo o procedimento estabelecido na NBR NM 67 (ABNT,1998): Concreto - Determinação da consistência pelo abatimento do tronco de cone.

A determinação da massa específica do concreto em seu estado fresco foi realizada através do procedimento descrito na NBR 9833 (ABNT, 2009): Concreto fresco - Determinação da massa específica, do rendimento e do teor de ar pelo 
método gravimétrico.

Os corpos de prova, que foram utilizados nos ensaios do concreto endurecido foram os cilíndricos, e foram moldados seguindo as especificações da NBR 5738 (ABNT, 2015): Concreto - Procedimento para moldagem e cura de corpos de prova. Após a moldagem os corpos de prova foram deixados no molde e colocados em uma superfície livre de vibração e cobertos por um período de $24 \mathrm{~h}$, para que não houvesse perca de água. Após essas $24 \mathrm{~h}$ os corpos de prova foram desmoldados e colocados em um tanque preenchido com água e, permaneceram ali até a data de seu rompimento.

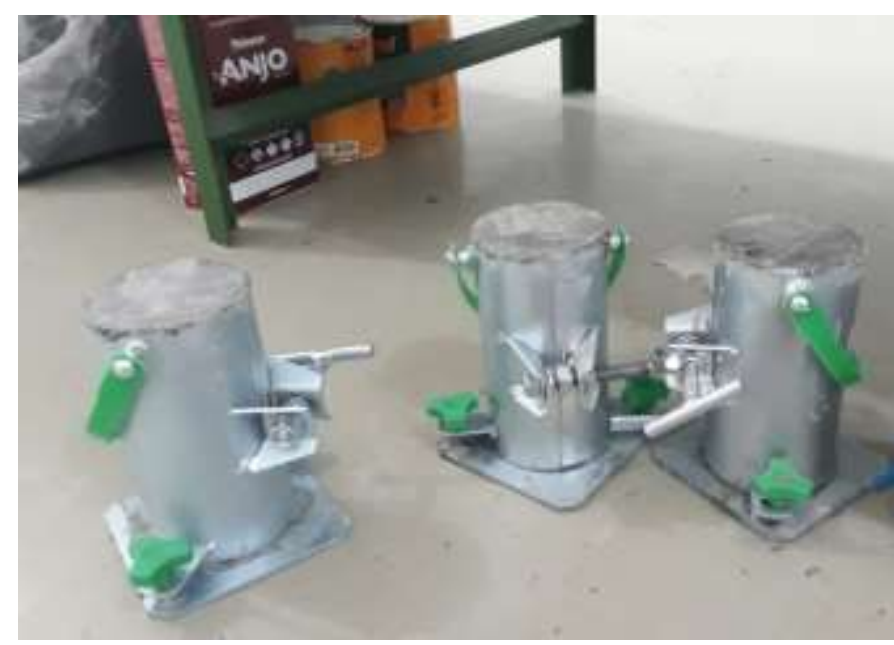

Figura 3 - Moldagem dos Corpos de Prova

Fonte: O próprio autor

A determinação da resistência à compressão do concreto ocorreu pelo rompimento dos corpos de prova, segundo método da NBR 5739 (ABNT, 2018): Concreto - Ensaios de compressão de corpos-de-prova cilíndricos.

\section{RESULTADOS E DISCUSSÕES}

TRABALHABILIDADE

O ensaio para determinar a trabalhabilidade do concreto produzido foi realizado segundo o procedimento estabelecido na NBR NM 67 (ABNT,1998): Concreto - Determinação da consistência pelo abatimento do tronco de cone. 
O ensaio foi realizado para todos os traços confeccionados e, o valor do slump obtido para o concreto convencionalde referência $(1: 3,93)$ não foi fixado para os próximos traços que foram produzidos com o aditivo incorporador de ar, isso porque um dos mecanismos de ação do aditivo incorporador é justamente, interferir na trabalhabilidade do concreto, ou seja, cada dosagem de concreto com porcentagens variadas de aditivo teriam também variados valores de slump. A imagem a seguir apresenta os dados obtidos.

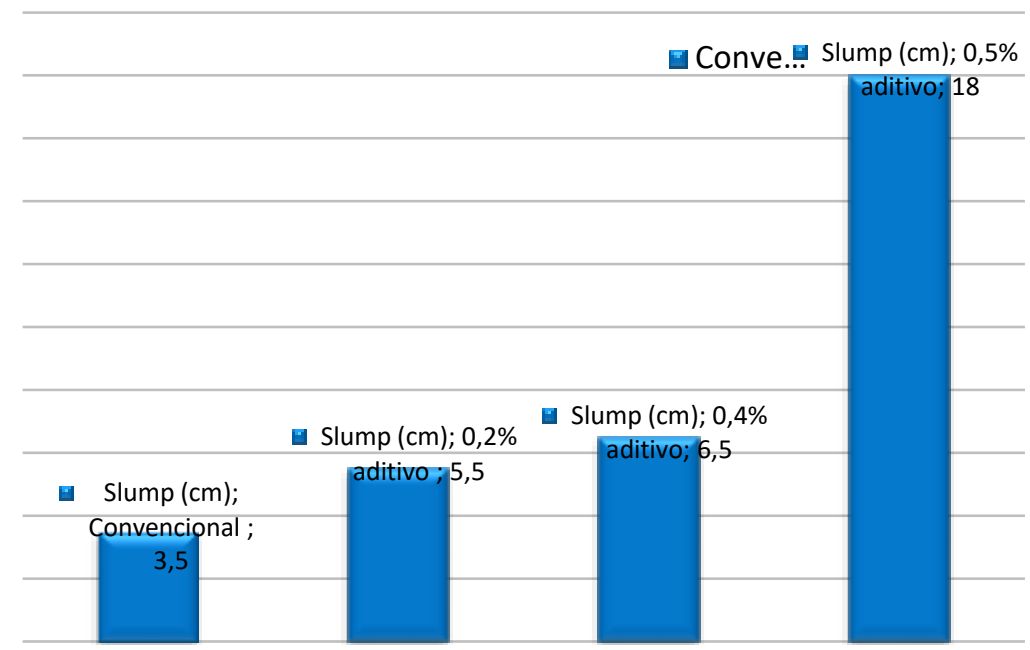

Figura 4 - Trabalhabilidade do Concreto

Fonte: O próprio autor

Com base nos dados obtidos é possível ver um aumento progressivo de slump para os concretos com ar incorporado, aumento esse que é mais significativo no concreto com $0,5 \%$ de aditivo. Comparando-se o concreto convencional de referência com o concreto com $0,5 \%$ de incorporador de ar pode-se ver um grande aumento de trabalhabilidade de $3,5 \mathrm{~cm}$ para $18 \mathrm{~cm}$, sendo assim é possível concluir que $\mathrm{o}$ aditivo incorporador de ar influencia diretamente na trabalhabilidade do concreto, aumentando-a.

\section{MASSA ESPECÍFICA}

A determinação da massa específica do concreto em seu estado fresco foi 
realizada através do procedimento descrito na NBR 9833 (ABNT, 2009): Concreto fresco - Determinação da massa específica, do rendimento e do teor de ar pelo método gravimétrico.

O ensaio da determinação da massa específica, foi realizado para todos os traços dos concretos em seu estado fresco, logo após a sua confecção, a imagem a seguir expressa os resultados obtidos:

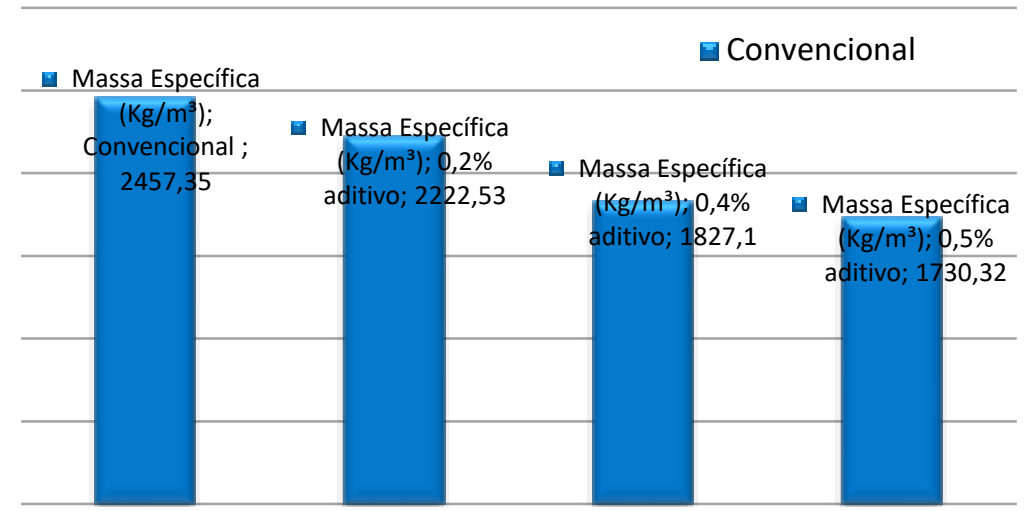

Figura 5 - Massa Específica do Concreto

Fonte: O próprio autor

Através dos resultados obtidos pode-se observar que o uso do aditivo no concreto reduz a sua massa específica, quanto maior o teor de aditivo utilizado maior foi a redução da massa específica, comparando-se o concreto convencional de referência com o concreto com 0,5\% de incorporador de ar é possível ver que a massa específica passou de $2457,35 \mathrm{~kg} / \mathrm{m}^{3}$ para $1730,32 \mathrm{~kg} / \mathrm{m}^{3}$, comprovando então a ação do aditivo em reduzir a massa específica do concreto.

\section{RESISTÊNCIA À COMPRESSÃO}

A determinação da resistência à compressão do concreto ocorreu pelo rompimento dos corpos de prova, segundo método da NBR 5739 (ABNT, 2018): Concreto - Ensaios de compressão de corpos-de-prova cilíndricos.

Os 36 corpos de prova confeccionados foram rompidos na empresa Minerocha Catarinense, sendo para cada traço três corpos de prova rompidos aos 7 , 
14 e 28 dias, os valores obtidos estão expressos no gráfico abaixo:

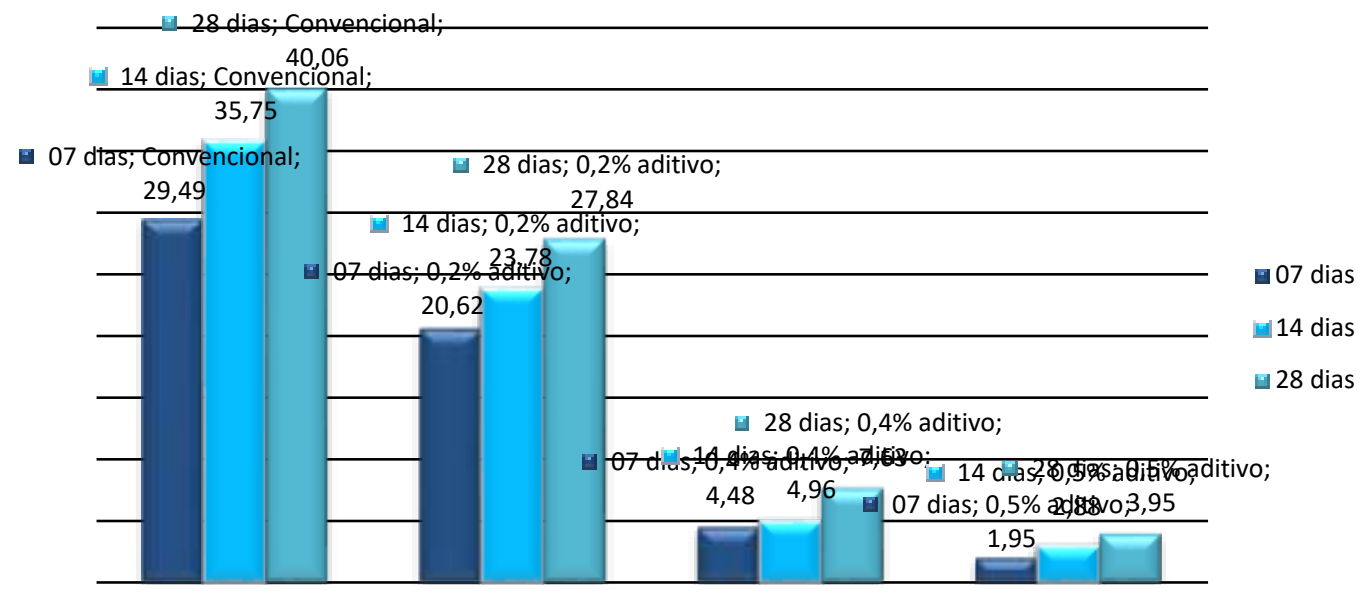

Figura 6- Resistência à Compressão

Fonte: O próprio autor

Com base nos dados obtidos após o rompimento dos corpos de prova, foi possível visualizar um aumento de resistência dos 07 para os 14 e então para os 28 dias em todos os traços confeccionados. Comparando-se o concreto convencional de referência com o concreto com 0,5\% de aditivo incorporador de ar pode-se perceber uma diminuição expressiva de resistência, passando de 40,06 MPa para apenas 3,95 MPa, ou seja, verifica-se que o aditivo incorporador de ar tem grande influência na resistência à compressão do concreto,

\section{CONCLUSÃO}

A utilização do concreto é muito ampla na construção civil, pois apresenta boas características como a resistência à compressão, e seus materiais constituintes são fáceis de encontrar, aliado ao aço também se torna resistente à tração, sendo assim é um material de grandes vantagens nas construções em geral.

Com o desenvolvimento de novas tecnologias e, também novos materiais, os estudos para novas confeç̧ões de concreto vêm se tornando comuns, e hoje vemos concreto com material reciclável, concreto com argila expandida, concreto 
com isopor, entre muitos outros que são utilizados para diversas finalidades como para isolamento térmico e acústico por exemplo.

Dentro dos tipos de concreto está o concreto leve com ar incorporado, uma alternativa para casos onde se queira diminuir o peso das edificações. Devido às diversas microbolhas de ar presentes no concreto, ele se torna mais poroso, e logo mais leve, sua principal utilização é para obras em que se necessita do concreto com resistência ao gelo e ao degelo, porém, o aditivo usado nesse tipo de concreto pode também ser utilizado para diminuição do peso dos elementos de concreto.

Com base nos dados e resultados obtidos através dos ensaios realizados, percebeu-se que o aditivo incorporador de ar tem diferentes mecanismos de ação no concreto. Foi possível perceber que influencia diretamente a trabalhabilidade, massa específica e a resistência à compressão do concreto.

A utilização do aditivo incorporador de ar também acrescenta em custo no concreto, isso claro, pois sua aquisição também tem um valor, porém de acordo com os dados obtidos é possível perceber que esse aumento de custo não é exorbitante, passando de $R \$ 102,81$ para apenas $R \$ 102,85$, claro que quanto maior o volume de concreto mais perceptível será a diferença de valor, porém é válido considerar o uso do aditivo em casos onde de necessite de suas vantagens, pois o custo não é de extremo aumento e pode ser compensado em outras variáveis da obra.

No que se refere à trabalhabilidade, percebeu-se que o concreto ficou mais trabalhável à medida que se aumentou a quantidade de aditivo utilizado, ou seja, quanto mais aditivo for adicionado à mistura, mais trabalhável ele se torna. Referente à massa específica, foi possível notar uma diminuição considerável da mesma nas maiores quantidades de aditivos utilizados, ou seja, quanto mais aditivo se usa, mais leve o concreto se torna, isso em função de uma maior quantidade de micro-bolhas de ar que se formam em sua estrutura. E por fim, no que se refere à resistência a compressão, os resultados comprovam que em função das bolhas de ar introduzidas no concreto e, consequentemente aumento do seu número de vazios, a resistência à compressão sofre uma significativa diminuição, ou seja, quanto maior a quantidade de ar introduzido no concreto através do aditivo menor é a sua resistência a compressão.

A diminuição da massa específica nos concretos com ar incorporado classificou os concretos com $0,4 \%$ e $0,5 \%$ de aditivo incorporador de ar como 
concreto leve de acordo com a NBR 8953 (ABNT, 2015) já que sua massa específica ficou abaixo de $2000 \mathrm{~kg} / \mathrm{m}^{3}$, o concreto com $0,2 \%$ de aditivo apresentou diminuição da massa em relação ao concreto convencional de referência, porém não se classificou como leve em função de sua massa ser acima de $2000 \mathrm{~kg} / \mathrm{m}^{3}$.

Sendo assim, chega-se à conclusão de que, o aditivo incorporador de ar produz concretos classificados como leves de acordo com a NBR 8953 (ABNT, 2015), porém, também se comprova uma drástica diminuição de sua resistência à compressão, quanto mais leve menos resistente o concreto se torna.

O concreto com 0,2\% de aditivo incorporador apresentou uma resistência à compressão mais próxima que a do convencional de referência, porém não se enquadrou na classificação de concreto leve. Os concretos com 0,4\% e 0,5\% de aditivo incorporador se classificam como concretos leves, porém não apresentaram resistência à compressão satisfatória próxima do concreto convencional de referência para que pudesse ser utilizado com função estrutural. Dessa maneira, de acordo com os dados obtidos no trabalho, o concreto leve com ar incorporado tem sua utilização recomendada para enchimento e vedação de paredes e, em casos onde se deseje ou necessite de um concreto mais trabalhável, porém não podendo ser utilizado para fins estruturais.

\section{REFERÊNCIAS}

ASSOCIAÇÃO BRASILEIRA DE NORMAS TÉCNICAS. NBR NM 67: Concreto Determinação da consistência pelo abatimento do tronco de cone. Rio de Janeiro, 1998.

ASSOCIAÇÃO BRASILEIRA DE NORMAS TÉCNCAS. NBR 5738: Concreto Procedimento para moldagem e cura de corpos de prova. Rio de Janeiro, 2015.

ASSOCIAÇÃO BRASILEIRA DE NORMAS TÉCNCAS. NBR 5739: Concreto - Ensaio de compressão de corpos-de-prova cilíndricos. Rio de Janeiro, 2018.

ASSOCIAÇÃO BRASILEIRA DE NORMAS TÉCNICAS. NBR 9833: Concreto fresco Determinação da massa especifica, do rendimento e do teor de ar pelo método gravimétrico. Rio de Janeiro, 2008.

BARBAR, Joseph Salem. Influência do teor de ar incorporado no desempenho de concretos com diferentes teores de agregados. 2016. 149 f. Tese (Doutorado em 
Arquitetura e Urbanismo - área de arquitetura, urbanismo e tecnologia) - Curso de Doutorado em Arquitetura, Urbanismo e Tecnologia. USP, Universidade de São Paulo, São Carlos.

DIPROTEC, Produtos técnicos para construção. Aditivos Incorporadores de ar. Disponível em: <http://www.diprotec.com.br/produto/aditivos-incorporadores-dear/>. Acesso em: 22 mar. 2018.

LIMA, Flávio Barboza de; BARBOZA, Aline da Silva Ramos; GOMES, Paulo Cesar Correia. Produção e Controle de Qualidade do Concreto. 1. ed. Alagoas: EDUFAL, 2003.

MC BAUCHEMIE. Ficha técnica Centramet Air 200. Disponível em: <http://www.mcbauchemie.com.br/wp-content/uploads/2013/12/centrament-air-200-112015.pdf>. Acesso em: 17 mai. 2018.

NEVILLE, A. M. Propriedades do Concreto. 5. ed. Porto Alegre: Bookman, 2016.

PINHEIRO, Antonio Carlos da Fonseca Bragança; CRIVELARO, Marcos. Materiais de Construção. 2. ed. São Paulo: Érica, 2016.

ROSSIGNOLO, João Adriano. Concreto leve estrutural: produção, propriedades, microestrutura e aplicações. 1.ed. São Paulo: Pini, 2009. 